\title{
Guidelines for safe and optimum neck dissection: a review article
}

\author{
Sheetal A. Murchite, Thakut Gowtham*, Abhinandan Milind Kadiyal, \\ Vaishali Vinayak Gaikwad, Ashutosh Tiwari
}

Department of Surgery, Dr. D. Y. Patil Medical College and Hospital Research Center, Kolhapur, Maharashtra, India

Received: 20 February 2021

Revised: 02 March 2021

Accepted: 05 March 2021

\section{*Correspondence:}

Dr. Thakut Gowtham,

E-mail: gowtham887@gmail.com

Copyright: ( ) the author(s), publisher and licensee Medip Academy. This is an open-access article distributed under the terms of the Creative Commons Attribution Non-Commercial License, which permits unrestricted non-commercial use, distribution, and reproduction in any medium, provided the original work is properly cited.

\begin{abstract}
Head and neck cancer is the sixth most common cancer worldwide. The single most important factor affecting prognosis for squamous cell carcinoma is the status of the cervical lymph nodes. Metastasis to the regional lymph nodes reduces the 5-year survival rate by $50 \%$ compared with that of patients with early-stage disease. The American cancer society reports that $40 \%$ of patients with squamous carcinoma of the oral cavity and pharynx present with regional metastases to the cervical lymph nodes. This activity presents the steps for safe and optimum neck dissection. Objectives of the study were to identify the anatomical structures in neck dissection, review the complications of head and neck surgery and summarize the importance of care coordination and to improve outcomes for patients undergoing head and neck surgery.
\end{abstract}

Keywords: Neck dissection, Ca thyroid, Ca oral cavity

\section{INTRODUCTION}

\section{Historical aspects}

The first radical neck dissection was described and performed by George Washington Crile at the Cleveland clinic in 1906. ${ }^{1,2}$ The revolutionary procedure marked a great step forward in the treatment of metastatic neck diseases. At the time, Crile, a founding member of both Cleveland clinic and the American college of surgeons, was already well known for his work in thyroidectomies, of which he performed more than 25,000 in his career.

As performed by Dr Crile, the radical neck dissection called for the removal of all lymph nodes on one side of the neck, as well as the spinal accessory nerve, internal jugular vein and sternocleidomastoid muscle. ${ }^{1-3}$ The main drawback to this procedure was shoulder dysfunction, which occurred due to sacrificing of the accessory nerve. ${ }^{2}$ Further practitioners eventually established more measures that are conservative.
In the 1940's and 50s, Hayes Martin, performed revolutionary neck dissections on a routine basis in order to manage metastasis in neck. ${ }^{4}$ His method also resected the spinal accessory nerve, the internal jugular vein, the sternocleidomastoid muscle and the submandibular gland. ${ }^{1,3,4}$ The remaining structures, including the carotid arteries, vagus nerve, hypoglossal nerve, brachial plexus and phrenic nerve were left intact.

In the early 1960s, an Argentinean cosmetic surgeon, Oswaldo Suarez explained the facial compartments in the neck and facial envelope covering a number of lymph nodes. ${ }^{5}$ He proposed a modification of Crile and Martin's radical neck dissection, which he termed as functional neck dissection. ${ }^{5}$ Suarez's method was to eliminate a selected group of lymph nodes and preserve the vital structures, like the accessory nerve, jugular vein and sternocleidomastoid muscle that Crile's procedure had designated for extraction. This method was further popularized in Europe by Ettore Bocca and Cesar 
Gavilian, and in the United States by Richard Jesse, Alando Ballantyne and Robert Byers. ${ }^{6}$

\section{THE MODIFICATIONS TO THE REVOLUTI- ONARY NECK DISSECTION ${ }^{7-11}$}

Type I: The spinal accessory nerve (cranial nerve) is preserved.

Type II: The spinal accessory nerve (cranial nerve) and the internal jugular vein are preserved.

Type III: The spinal accessory nerve (cranial nerve) internal jugular vein and the sternocleidomastoid muscle are preserved. ${ }^{1}$

\section{EVOLUTION OF THE NECK DISSECTION}

In 1880, Kocher planned removing nodal metastasis. George Crile explained the classification of revolutionary neck dissection (RND) in 1906. ${ }^{2}$ In 1933 and 1941, Blair and Martin popularized the RND. ${ }^{4}$ In 1953, Pietrantoni suggested sparing the spinal accessory nerves. Bocca and Pignataro explained the "functional neck dissection" (FND) in $1967 .{ }^{6}$ In 1975, Bocca established oncologic safety of the FND compared to RND in 1967.6,12 Medina, Robbins, and Byers respectively planned classifications of neck dissections in 1989, 1991 and $1994:^{3,8-11,13}$ In 1991, official record of the academy's committee for head and neck surgery and oncology standardizing revolutionary neck dissection terminology. ${ }^{7-11,13}$

\section{KNOWLEDGE OF SURGICAL ANATOMY OF NECK}

Understanding the regional lymphatic drainage pathways is critical when planning which type of neck dissection will be employed. A supraomohyoid neck dissection is done when there is risk for micro-metastasis in levels I, II, and III in patients getting operated. ${ }^{2,14}$ The boundaries of levels I (submental and submandibular), II (upper jugular nodal chain), and III (mid jugular nodal chain) are defined as follows:

Level Ia: The medial aspect of anterior belly of the digastric muscles forms lateral boundary, and ends at an anatomic midline medially which is a line drawn from the mandible to the hyoid bone. ${ }^{3}$

Level Ib: Bounded by the lateral aspect of the anterior belly of the digastric muscle, the medial aspect of the posterior belly of the digastric and stylohyoid muscles, and the inferior border of the mandibular body superiorly.

Level IIa: Bounded anteriorly and superiorly by the posterior belly of the digastric and stylohyoid muscles, posteriorly by the vertical plane defined by the spinal accessory nerve and sternocleidomastoid muscle (SCM), and inferiorly by the horizontal plane defined by the inferior border of the hyoid bone. ${ }^{2,4}$
Level IIb: Bounded anteriorly by the jugular vein and inferiorly by the vertical plane defined by the spinal accessory nerve, posteriorly by the posterior border of the SCM, and superiorly by the skull base. ${ }^{3}$

Level III: Bounded superiorly by the horizontal plane defined by the inferior border of the hyoid bone, inferiorly by the horizontal plane defined by the inferior border of the cricoid cartilage and/or the omohyoid muscle as it crosses the internal jugular vein, anteriorly by the lateral border of the sternohyoid muscle, and posteriorly by the posterior border of the SCM. ${ }^{2,4}$

\section{DISCUSSION}

\section{Incision}

The exact location and type of skin incision will depend on the site of the primary tumor and whether a unilateral or bilateral neck dissection is planned. The following are the main goals to be achieved by the skin incision: Allow adequate exposure of the surgical field. Assure adequate vascularization of the skin flaps. Protect the carotid artery if the sternocleidomastoid muscle has to be sacrificed. Include scars from previous procedures (e.g., surgery, biopsy, etc.). Consider the location of the primary tumor. Facilitate the use of reconstructive techniques. Contemplate the potential need of postoperative radiotherapy and produce acceptable cosmetic results (Figure 1).

\section{Macfee incision}

Advantages of Macfee incision are good supply for flaps and excellent for previously irradiated neck. Disadvantages of it is exposure to neck structures is not good.

Most commonly used incision used for MNDSchobinger (singe Y), advantages are like avoids crossing of double $\mathrm{Y}$ and protects carotid artery. Disadvantages are dissection of supraclavicular area is a little bit of difficult.

\section{Raising the flaps}

After the incision is completed, the skin flaps are elevated deep to the platysma muscle, preserving the superficial layer of the cervical fascia. Preservation of the external lymphatic envelope allows further fulfilment of the basic anatomical principle of the functional approach (i.e., removal of the fascial walls of the lymphatic container along with the lymphatic tissue of the neck) (Figure 2).

Superior-inferior border of mandible, Inferior-Clavicle, Anterior-Mid-line of neck and posterior-Anterior border of trapezius.

The flaps must be protected by means of wet surgical sponges. Frequent moistening of the sponges will help to 
keep the skin flaps in good condition throughout the operation. It should be remembered that this might be a long operation since neck dissection is often performed in conjunction with removal of the primary tumour and, in some instances, reconstructive procedures. Thus, all efforts should be made to preserve the skin in good condition until the end of the procedure.

A

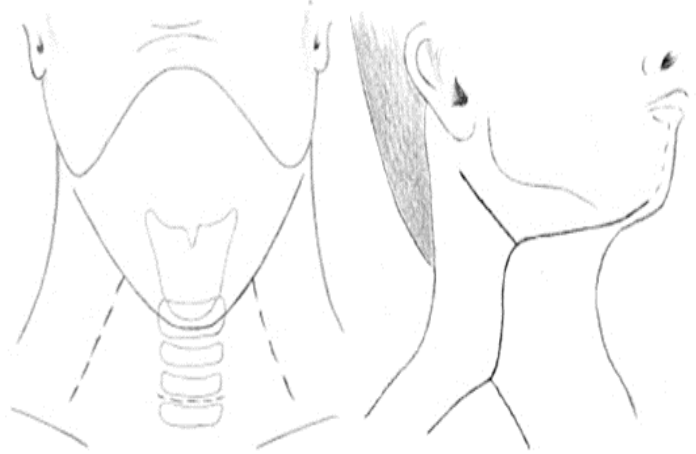

C

E
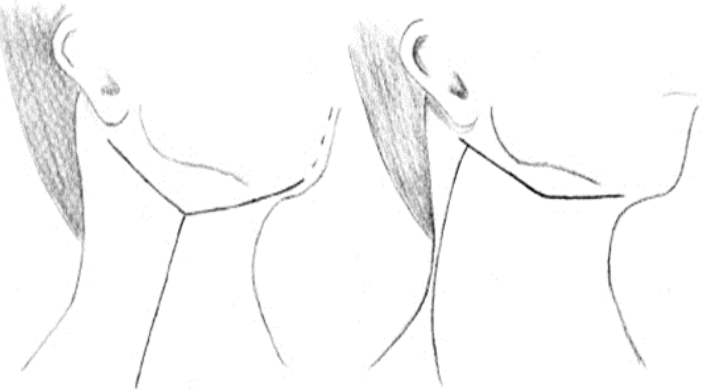

B

G
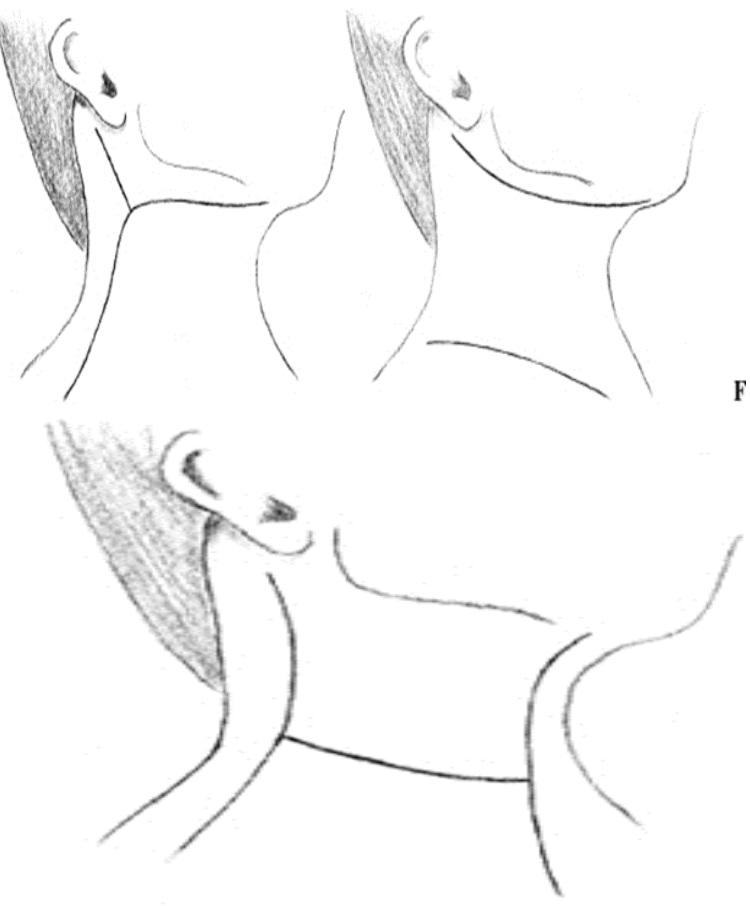

Figure 1: (A) Gluckincision for unilateral and bilateral neck dissection, $(B)$ double-Y incision of Martin, (C) single-Y incision, (D) Schobinger incision, (E) Conley incision, (F) Mac Fee incision and (G) $\mathbf{H}$ incision.

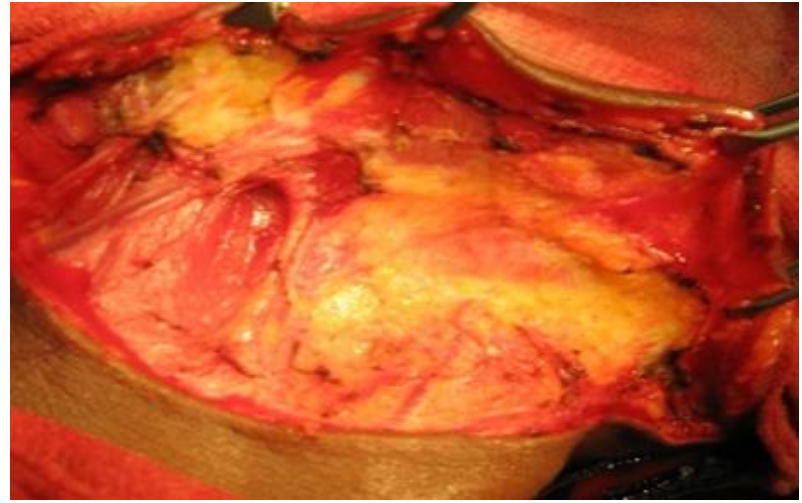

Figure 2: Flap raised and neck exposed.

\section{Lymph node dissection}

The skin is infiltrated with adrenaline solution in saline or $2 \%$ lignocaine both in 1:2,00,000 concentration (to minimize the skin bleeding).

The horizontal skin incision is taken, the skin and platysma are cut at same level for better wound approximation, Identify external jugular vein and greater auricular nerve over the SCM. Care to be taken to prevent injury to external jugular vein and greater auricular nerve.

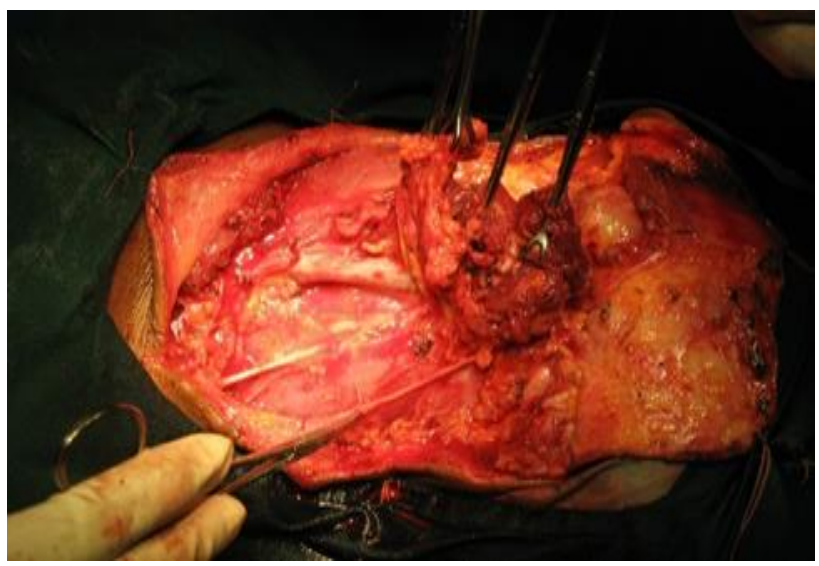

Figure 3: Spinal accessory nerve in neck.

\section{Anterior triangle dissection}

Sternocleidomastoid muscle is cut $1 \mathrm{~cm}$ above the clavicle. If IJV is to ligated the vessels is cleared all around on left side level four lymph nodes are cleared after ligated or clipping the fibrofatty tissue to avoid injury to chyle duct especially on left side. The sternocleidomastoid muscle and lymph nodes retracted superiorly from carotid sheath and level IV and III cleared, cervical roots entering the dissected tissue can beat away from phrenic nerve. Sternocleidomastoid is then cut as high as possible close to mastoid spinal accessory nerve dissected from the muscle after cutting its branches to muscle. The level II lymph nodes are cleared from deep muscles of neck. 


\section{Submandibular triangle dissection}

Identify the marginal mandibular nerve $1.5 \mathrm{~cm}$ below and in front at angle of mandible. It is traced anteriorly towards its entry in to neck flap and posteriorly as it entering in to neck from parotid tissue. Retract the posterior belly of digastric inferiorly and identify the fascial artery, ligate it continuity and cut. The fascial vein ligated at the level entering to internal jugular vein. Hypoglossal nerve and vein comitantes identified after tracing the submandibular gland until mylohyoid muscle. ${ }^{21}$ Superficial lobe is dissected off the mylohyoid muscle and the muscle is retracted to dissect deep lobe dissected off the inguinal nerve and its branches to gland ligated. The duct is ligated and gland with all the lymph nodes removed.

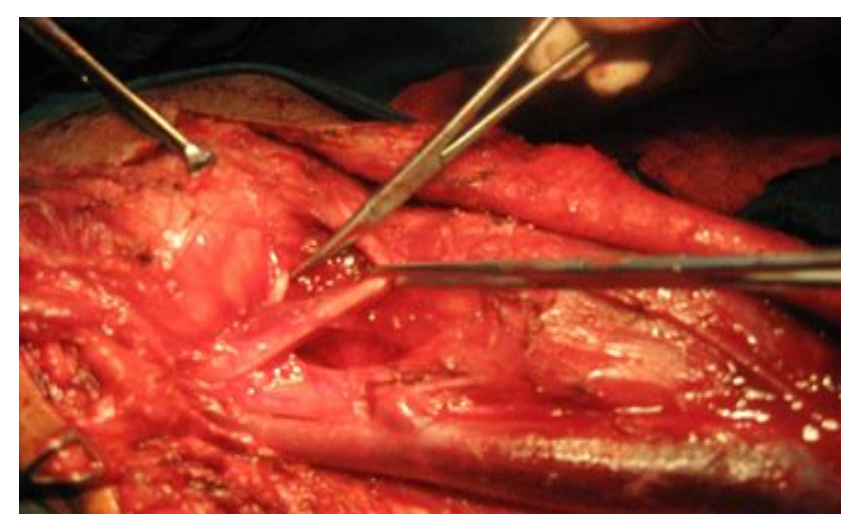

Figure 4: Hypoglossal nerve.

\section{Submental triangle dissection}

Level I a lymph nodes dissected between both anterior bellies of the digastric muscles and hyoid bone inferiorly. All the fibrofatty dissected exposing mylohyoid muscle.

\section{Selective neck dissection}

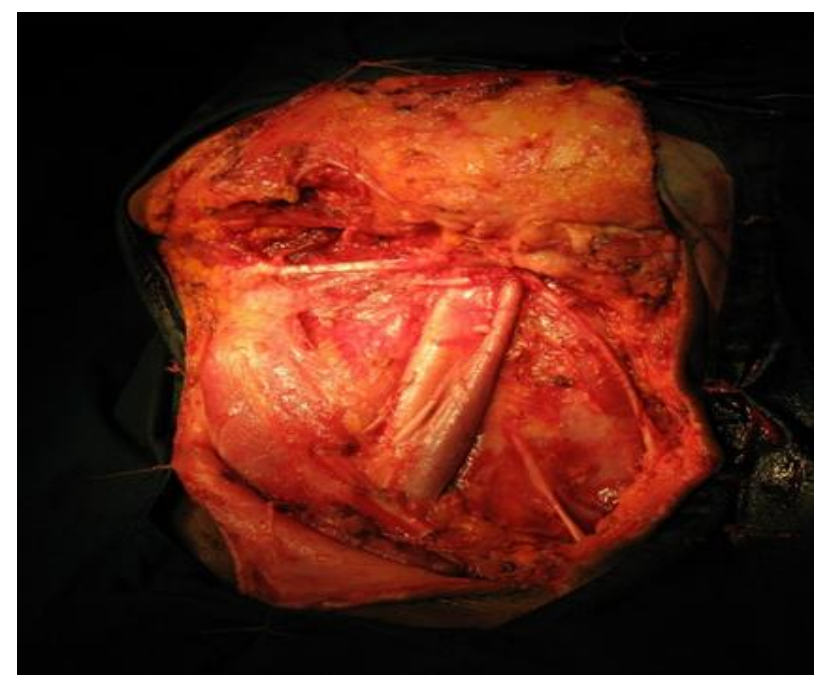

Figure 5: All level lymph nodes dissected flap raised and neck exposed.

\section{Level Ia-Ib neck dissection}

After flap elevation, expose the anterior belly of the digastric muscle by making a midline incision from below the mentum to the hyoid bone. It is important to include all the fibrofatty contents from the contralateral medial edge of the digastric muscle. The elevation continues to the medial aspect of the submandibular gland to complete the level Ia dissection.

The marginal mandibular branch of the facial nerve can be located approximately one $\mathrm{cm}$ inferior to angle of the mandible. Incisions brought across the neck are always two fingerbreadths below the angle to prevent inadvertent injury to this nerve. The marginal mandibular branch of the facial nerve lies between the superficial layer of the deep cervical fascia and the adventitia investing the anterior facial vein. The superficial layer of the deep cervical fascia is incised at the inferior border of the submandibular gland. It must be elevated and may be tacked to the platysma muscle to aid in elevation.

Care must be taken to preserve the marginal mandibular branch of the facial nerve and reflect it superiorly, along with the superficial layer of the deep cervical fascia, and to remove any submandibular retro vascular (perifacial) lymph nodes in the area. This is accomplished by developing a plane between the vein and superficial layer of the deep cervical fascia, keeping the fat pad that contains the facial nodes down in the specimen, along with the submandibular gland, and elevating and protecting the nerve.

At this point, the anterior belly of the digastric muscle is isolated, and the gland and fibrofatty contents of level Ia are brought posteriorly across the mylohyoid muscle.

Retract the mylohyoid muscle; identify and preserve the lingual and hypoglossal nerves; then identify, ligate, and divide the submandibular duct, submandibular ganglion, and corresponding vasculature. Level I is released and left pedicled by the inferior fibrofatty attachments to levels II and III.

\section{Level II-III neck dissection}

Identify the posterior belly of the digastric muscle, creating the digastric tunnel back to the mastoid tip under the SCM. Incise the investing fascial layer along the anterior border of the SCM, ligating and dividing the external jugular vein in the process. An attempt should be made to preserve the greater auricular nerve, if not involved with disease. Unwrap the SCM from its investing fascia. This is accomplished along a broad, superior-to-inferior plane, from the digastric muscle superiorly to the omohyoid muscle inferiorly.

Identify the spinal accessory nerve at its entrance into the SCM, and trace it under the posterior belly of the digastric muscle. The spinal accessory nerve typically 
passes lateral to the internal jugular vein just before diving under the posterior belly of the digastric muscle. The nerve will occasionally bisect or run deep to the jugular vein. The spinal accessory nerve is released from the surrounding soft tissue, and then level IIb is released from the skull base, the back of the jugular vein, the SCM, and the deep cervical fascia. Level IIb is left attached to IIa and brought under spinal accessory nerve.

Once the investing fascial layer is elevated off the SCM down to the level of the deep cervical rootlets, the dissection is taken medially across the rootlets from the omohyoid muscle to the spinal accessory nerve superiorly. Care must be taken to avoid injuring the spinal accessory nerve in this area as it exits the SCM posteriorly. Dissect levels II and III medially in a plane lateral to the cervical rootlets and the carotid sheath, which invests the carotid artery, internal jugular vein, and vagus nerve.

Once the elevation reaches the jugular vein, the fascia from the internal jugular vein is unwrapped. Branches of the vein may be ligated and divided as the specimen is brought medially. The ansa cervicalis will be transected during the inferior dissection as the specimen is brought across the jugular vein to the lateral aspect of the strap muscles. Superiorly, the hypoglossal nerve, which runs lateral to carotid artery and medial to jugular vein, must be protected under the digastric muscle. The ansa hypoglossi will likely need to be transected as specimen is brought medially to hyoid bone and strap musculature.

The specimen is then dissected away from the hypoglossal nerve and posterior belly of the digastric muscle until it can be easily removed. The anterior dissection will meet with the posterior dissection as the specimen is brought across the strap muscles, carotid artery, and jugular vein.

\section{Neck dissection in ca thyroid}

A standard collar incision is made approximately two fingerbreadths above the sternal notch. The vertical extent of the incision coursing superiorly along the anterior border of the sternocleidomastoid muscle depends on the extent of metastatically involved lymph nodes indicated by preoperative ultrasonography. ${ }^{15,16}$ If level II nodes are dissected, the incision is significantly longer than if only the usual compartments are dissected. ${ }^{17,18}$ Once the incision is made, the superior subplatysmal flap is dissected medially to the midline up to the thyroid cartilage and as far superiorly as necessary anterior to the carotid artery and internal jugular vein. ${ }^{19,20}$ A sharp towel clamp is used to secure the dermis of the flap to the surgical drapes at the chin.

\section{Exposure internal jugular vein and carotid artery}

The plane between the sternocleidomastoid muscle and the strap muscles is opened by dissecting the entire medial border of the sternocleidomastoid muscle, which is retracted laterally with two goiter retractors throughout the dissection. The omohyoid muscle is identified, encircled, dissected superiorly and laterally, and excised, thereby exposing the IJV and common carotid artery.

\section{Dissection of IJV to locate floor of neck}

As the IJV is further mobilized superiorly and inferiorly, it is retracted medially and elevated anteriorly using a vein retractor. This exposes the areolar tissue behind the IJV, extending down onto the anterior scalene muscle. This space is easily entered and bluntly dissected, facilitating identification of the phrenic nerve running vertically on the anterior scalene muscle. The nerve identity may be confirmed by a gentle pinch, causing contraction of the diaphragm and a hiccup. ${ }^{21}$

\section{Dissection and protection of carotid sheath structures and thoracic duct}

The transverse cervical artery (a branch of the thyrocervical trunk) courses laterally across the anterior scalene muscle, anterior to the phrenic nerve, and may be a useful guide to it. ${ }^{22}$ This artery may be sacrificed if necessary, care-fully protecting the underlying nerve.

During mobilization of the IJV it should be handled gently to avoid venotomy with attendant bleeding and risk of air embolism. The remainder of the dissection is accomplished with a combination of blunt, sharp, and extensive but careful use of cautery dissection. The carotid artery and vagus nerve are identified and protected throughout remainder of dissection along IJV.

As the dissection progresses inferiorly along the lateral border of the IJV, care must be taken not to dissect into the subclavian vein as it joins the IJV. At the base of the left side of the neck, looping up a short distance behind the IJV from medial to lateral, is the thoracic duct. It descends to enter the confluence of the IJV and subclavian vein. This is very vulnerable to injury, especially if the commonly encountered, enlarged, metastatically involved nodes obscure the surgeon's view. However, if injured in adults, the thoracic duct may be ligated without harm. ${ }^{23,24}$

The inferior lateral compartment nodes are elevated superiorly by dissecting laterally across the base of the neck, encountering small veins that can be clipped or ligated. This fully exposes the anterior scalene muscle and, with further blunt dissection and elevation anteriorly of the nodal packet, the brachial plexus can be identified palpably and visually, coursing between the anterior and middle scalene muscles.

\section{Cervical plexus preservation}

The packet is then retracted anteromedially as it is released from its lateral attachments. The individual 
nerves of the cervical plexus, which are all sensory nerves (except the phrenic nerve and ansa cervicalis), are encountered and preserved. The nodes posterior to this plexus are separated from their loose posterior attachments and delivered between the nerves. ${ }^{25,26}$

\section{Spinal accessory nerve location and orientation}

Superior to the cervical plexus nerves is the spinal accessory nerve that courses in an obliquely vertical course at this level. Careful use of the cautery at low power will stimulate this nerve prior to actually encountering it. Once stimulation of the trapezius is apparent, the nerve can be identified and carefully dissected superiorly without use of cautery.

Once the nodes from this level have been separated from the vessels and spinal accessory nerve, the entire packet of nodes is excised, oriented, and submitted to pathology, completing the dissection

\section{Nerves}

Vagus $(X)$ : If the vagus nerve is injured in the neck, unilateral vocal cord paralysis will result, as the recurrent laryngeal nerve is part of the vagus at this level.

Spinal accessory $(X I)$ : The principal disability with the XI nerve is shoulder syndrome, including weakness of the trapezius muscle with resultant reduced abduction of the shoulder, stiffness, and abnormal scapular rotation. ${ }^{27}$

Phrenic: Damage to the phrenic nerve results in unilateral elevation of the diaphragm and possible compromise to respiratory function.

Hypoglossal (XII): A rare in jury to this nerve leads to dysfunction of the tongue and deviation of the tongue to the affected side. ${ }^{28}$

Sympathetic chain: Located posterior to the carotid sheath, dam- age to this structure leads to Horner syndrome. $^{28}$

Marginal mandibular branch of facial (VII): While damage to this nerve should be almost excluded by the extent of the dissection for PTC, its anatomic course dipping below the level of the mandible should be borne in mind. Damage causes a serious cosmetic drop of the corner of the mouth associated with drooling. ${ }^{28,29}$

Brachial plexus: Because of their deep location, coursing between the anterior and middle scalene muscles, injury to these nerves should be extremely rare, but could be serious, depending on the specific nerves affected.

Cutaneous cervical plexus: Damage to these nerves in the past has been an anticipated consequence of the operation. However, preserving these nerves can regularly be accomplished, preserving sensation to the upper and lateral chest.

\section{Vessels}

Carotid artery: Carotid laceration or rupture is usually associated with prior radiotherapy or markedly scarred reoperations. Stroke or fatality can result. Significant bradycardia can occur with dis- section around the carotid bulb at the bifurcation.

Internal jugular vein: Laceration or avulsion of small tributaries are bothersome but seldom serious and are usually repaired with vascular suture. The vein can be sacrificed unilaterally without serious concern. Air embolus must be prevented when patients are positioned in reverse Trendelenburg and an opening in the vein is caused.

\section{Lymphatics}

Injury to the thoracic duct can be remedied by ligation without complication in adults. However, a persistent high-volume chylous leak can be troublesome. Intraoperatively, the lymphatic fluid is nearly clear and colorless, in contrast to the milky character it becomes postoperatively after eating. A low-volume lymphatic leak may become evident in the first 2 to 4 days postoperatively, but often seals over the next few days. Administration of somatostatin can reduce the production of chyle. Similar but less prominent lymphatic trunks may be encountered just lateral to the base of the right internal jugular vein and must be managed in similar fashion to the thoracic duct. ${ }^{25,30-32}$

\section{Post-operative care}

After wound closure and the installation of a vacuum drain, the patient is put in a more or less upright position to reduce pain and discomfort due to swelling. After a bilateral operation, some form of airway management must be maintained, either by prolonged intubation, strict surveillance, or a tracheotomy.

Non-opioid analgesia is sufficient in most cases, and some form of thrombotic prophylaxis is recommended. Early mobilization is advised, as well as early onset of physical therapy of the shoulder to prevent a shoulder syndrome. It should be noted that most patients benefit from the latter whether or not the accessory nerve is either dissected or sacrificed.

\section{Management of complications}

The most prevalent complications of lymph node dissections are postoperative bleedings and wound infections. Most bleeding becomes visible within the first postsurgical hours by distension of the skin flaps and rapid filling of vacuum bottles with fresh blood and clots. If bleedings occur, the patient should be 
taken back to the operating room; the wound opened, irrigated and all possible bleeding controlled; and a new vacuum system installed before closing the wound again. It should be kept in mind that delay of an adequate intervention may lead to a compromised airway, and this must be avoided at all times.

Wound infection becomes apparent from the second to third postoperative day by redness, purulent discharge, wound dehiscence, elevated infection parameters in blood samples, and fever. In most cases, antibiotics and drainage are sufficient measures to manage these. In the previously irradiated patient, however, an infection may be complicated by an underlying skin flap necrosis, and this must be addressed by debridement and, if necessary, the use of a vascularized flap.

Chyle leakage may occur after dissection of level IV on both sides of the neck. It should be kept in mind that it is predominantly caused by a lesion of the thoracic duct in the left lower neck, but nevertheless, a clinically significant leakage may also be produced after dissection of the right lower neck, because major lymph vessels are also present in this area. Most leaks become present after the patient's first postoperative meal as the amount of drainage fluid increases and becomes whitish. If in doubt, performing a test on triglyceride content from a drained wound fluid sample can facilitate diagnosis. The risks associated with prolonged leakage are wound breakdown, skin flap necrosis, and metabolic sequelae.

If the surgeon encounters a chyle leak during surgery, it must be controlled directly by suturing or stapling, sometimes aided by application of fibrin or cyanoacrylate glue. ${ }^{26}$ Control of a major lesion may be attempted by transposition of a local muscle flap. Management of a postoperative chyle leakage is conservative, and the patient is first placed on a low-fat medium chain triglyceride enriched diet. If the result is unsatisfactory, total parenteral nutrition is advisable. If this also proves to be unhelpful, attention is directed toward the thoracic duct itself that may be blocked by percutaneous embolization or endoscopic thoracic ligation. ${ }^{27,28}$ In these circumstances, reoperation rarely leads to satisfactory results.

\section{CONCLUSION}

The surgeons should be knowing the detailed anatomy of the neck. Dissection should be done in anatomical planes to avoid injury to important nerves like vagus nerve, spinal accessory nerve, phrenic nerve, hypoglossal nerve and brachial plexus. En block removal of all levels of lymph nodes should be done to avoid recurrence.

Funding: No funding sources Conflict of interest: None declared

Ethical approval: Not required

\section{REFERENCES}

1. Lamb DD. Association of surgical technologist, radical neck dissection. Surgical technolog. 2010;448-54.

2. Crile G. Excision of cancer of the head and neck, with special reference to the plan of dissection based on 132 operations. JAMA. 1906;47:1780-4.

3. Beahrs O, Gossel J, Hollinshead W. Technic and surgical anatomy of radical neck dissection. Plastic Reconstructive Surg. 1957;19(3):261.

4. Martin H, Del Valle B, Ehrlich H, Cahan WG. Neck dissection. Cancer. 1951;4:441-99.

5. Suárez O. El problema de las metastasis linfaticas y alejadas del cancer de laringe e hipofaringe. Rev Otorrino-laryngol. 1963;23:83-99.

6. Bocca E, Pignataro O. A conservation technique in radical neck dissection. Ann Otol Rhinol Laryngol. 1967;76:975-87.

7. Muller CD, Newlands SD. Neck dissection: classifications, indications and techniques. The university of Texas medical branch, department of otolaryngology, grand rounds presentation. 2002.

8. Robbins KT, Medina JE, Wolfe GT, Levine PA, Sessions RB, Pruet CW. Standardizing neck dissection terminology. Official report of the Academy's Committee for Head and Neck Surgery and Oncology. Arch Otolaryngol Head Neck Surg. 1991;117(6):601-5.

9. Robbins KT, Clayman G, Levine PA, Medina J, Sessions R, Shaha A et al. Neck dissection classification update. Arch Otolaryngol Head Neck Surg. 2002;128:751-8.

10. Robbins KT, Shaha AR, Medina JE, Califano JA, Wolf GT, Ferlito A et al. Consensus statement on the classification and terminology of neck dissection. Arch Otolaryngol Head Neck Surg. 2008;134(5):536-8.

11. Robbins KT, Shannon K, Vieira F. Super selective neck dissection after chemoradiation: feasibility based on clinical and pathologic comparisons. Arch Otolaryngol Head Neck Surg. 2007;133(5):486-9.

12. Bocca E. Conservative neck dissection. Laryngoscope. 1975;85(9):1511-5.

13. Ferlito A, Robbins KT, Shah JP, Medina JE, Silver CE, Al-Tamimi et al. Proposal for a rational classification of neck dissections. Head Neck. 2011;33(3):445-50.

14. Lindberg R. Distribution of cervical lymph node metastases from squamous cell carcinoma of the upper respiratory and digestive tracts. Cancer. 1972;29:1446-9.

15. Stulak JM, Grant CS, Farley DR, Geoffrey B. Value of pre- operative ultrasonography in the surgical man- agement of initial and re-operative papillary thyroid cancer. Arch Surg. 2006;141(5):489-96.

16. Kouvaraki M, Shapiro S, Fornage BD, et al. Role of preoperative ultrasonography in the surgical management of patients with thyroid cancer. Surgery. 2003;134(6):946-955. 
17. Jemal A, Murray T, Ward E. Cancer statistics. CA Cancer J Clin. 2005;55(1):10-30.

18. Beahrs $\mathrm{OH}$, Woolner LB. The treatment of papillary carcinoma of the thyroid gland. Surg Gyne-col Obstet. 1959;108(1):43-8.

19. Frazell EL, Foote FW Jr. Papillary cancer of the thyroid: a review of 25 years of experience. Cancer. 1958;11(5):895-922.

20. Noguchi S, Murakami N. The value of lymph- node dissection in patients with differentiated thy- roid cancer. Surg Clin North Am. 1987;67(2):251-61.

21. Skolnik EM, Yee KF, Friedman M. The posterior triangle in radical neck surgery. Arch Otolaryngol. 196;102(1):1-4.

22. Schlumberger MJ. Papillary and follicular thy- roid carcinoma. N Engl J Med. 1998;338(5):297-306.

23. Hay ID, Thompson GB, Grant CS. Papillary thyroid carcinoma managed at the Mayo Clinic during six decades (1940-1999): temporal trends in initial therapy and long-term outcome in 2444 consecutively treated patients. World J Surg. 2002;26(8):879-85.

24. Beahrs OH, Gossel JD, Hollinshead WH. Technic and surgical anatomy of radical neck dissection. Am J Surg. 1955;90(3):490-516.

25. Sywak M, Cornford L, Roach P, Stalberg P, Sidhu S, Delbridge L. Routine ipsilateral level VI lymphadenectomy reduces postoperative thyroglobulin levels in papillary thyroid cancer. Surgery. 2006;140(6):1000-7.

26. Caron NR, Clark OH. Papillary thyroid cancer: surgical management of lymph node metastases. Curr Treat Options Oncol. 2005;6(4):311-22.

27. Mazzaferri EL, Kloos RT. Clinical review 1238: current approaches to primary therapy for papillary and follicular thyroid cancer. J Clin Endocrinol Metab. 2001;86(4):1447-63.

28. Uchino S, Noguchi S, Yamashita H, Watanabe S. Modified radical neck dissection for differentiated thyroid cancer: operative technique. World J Surg. 2004;28(12):1199-203.

29. Cobin RH, Gharib H, Bergman DA. Thyroid Carcinoma Task Force; American Association of Clinical Endocrinologists; American College of Endocrinology. AACE/AAES medical/surgical guide- lines for clinical practice: management of thyroid carcinoma [correction appears in Endocr Pract. 2008;14(6):802-03.

30. Beahrs O, Gossel J, Hollinshead W. Technic and surgical anatomy of radical neck dissection. Plastic Reconstructive Surg. 1957;19(3):261.

31. American Thyroid Association Guidelines Taskforce. Management guidelines for patients with thyroid nodules and differentiated thyroid cancer. Thyroid. 2006;16(2):1-33.

32. Shah JP. Patterns of cervical lymph node metastasis from squamous carcinomas of the upper aerodigestive tract. Am J Surg. 1990;160:405-9.

33. Kouvaraki MA, Lee JE, Shapiro SE, Sherman SI, Evans DB. Preventable reoperations for persistent and recurrent papillary thyroid carcinoma. Surgery. 2004;136(6):1183-91.

Cite this article as: Murchite SA, Gowtham T, Kadiyal AM, Gaikwad VV, Tiwari A. Guidelines for safe and optimum neck dissection-a review article. Int Surg J 2021;8:1394-401. 